\title{
Clin Obs Domain
}

National Cancer Institute

\section{Source}

National Cancer Institute. Clin Obs Domain. NCI Thesaurus. Code C154640.

Standardized qualitative and quantitative clinical observations about a patient. 